\title{
Experimental milling of olivine: Implications for ascent and eruption of kimberlite
}

\author{
Thomas J. Jones ${ }^{1}$ \& J. K. Russell ${ }^{2}$ \\ ${ }^{1}$ Department of Earth Sciences, Durham University, South Road, Durham, DH1 3LE, UK, \\ t.j.jones@durham.ac.uk; tomij7@gmail.com \\ ${ }^{2}$ Department of Earth, Ocean \& Atmospheric Sciences, University of British Columbia, Vancouver, British \\ Columbia, V6T 1Z4, Canada, jkr2002@gmail.com
}

\section{Introduction}

Kimberlite magmas entrain, transport and erupt large volumes of mantle-derived olivine grains. Characteristically, the olivine crystals found in kimberlite are rounded and ellipsoidal in shape. The origin of their ellipsoidal morphologies remains somewhat enigmatic given their origin from disaggregation of lithospheric mantle rocks. Explanations include rounding by magmatic corrosion and dissolution (Kamenetsky et al. 2008; Pilbeam et al. 2013) or mechanical milling (Arndt et al. 2006; Arndt et al. 2010; Russell et al. 2012; Jones et al. 2014; Brett et al. 2015). Here, we focus on mechanical processes that operate during turbulent mantle ascent, facilitating reshaping and resurfacing of olivine.

During transport orthopyroxene and other mantle minerals are assimilated by the kimberlite magma. One effect of the assimilation is to raise the melt's $\mathrm{SiO}_{2}$ content, thereby causing a reduction in $\mathrm{CO}_{2}$ solubility and the spontaneous exsolution of a $\mathrm{CO}_{2}$-dominated fluid phase (Brooker et al. 2011; Russell et al. 2012; Moussallam et al. 2015). This assimilation-driven exsolution of a fluid phase provides a continuous decrease in density, an increase in buoyancy, and an accelerating ascent. Additionally, there is strong evidence that, during kimberlite magma ascent through the mantle lithosphere, substantial mechanical modification of the suspended cargo occurs (Jones et al. 2014; Brett et al. 2015). Brett et al. (2015) hypothesized that the ascending dyke segregates into a turbulent gas-rich head where particleparticle interactions dominate followed by a trailing tail of less gas-charged magma. This ascending dyke continually modifies its cargo from initial disaggregation to ultimately, eruption. Here, we present data from a series of novel, scaled, analogue attrition experiments that inform on the rates, efficiency and timings of mechanical modification possible during transport through the mantle lithosphere.

\section{Methods and scaling}

Our experiments consist of a particle bed that contains disaggregated olivine crystals derived from mantle dunite. Before loading the particle feed, olivine grains were sieved to a restricted size range (500 $\mu \mathrm{m}-1 \mathrm{~mm}$ ) and washed with deionised water to remove any adhering particles. The particle bed in which the sample is loaded rests on a distributor plate that is connected to a compressed air supply allowing a controlled gas feed of $85 \mathrm{Lmin}^{-1}$ (Fig. 1). Above the bed lies a $1.2 \mathrm{~m}$ high tube where particles can rise and interact within a gas suspension. Lastly, the attrition tube is connected to a fine mesh screen and passed through a water collection trap to ensure that all the experimental run products are recovered, even micron size fragments. The attrition experiments were performed at nine different durations from 0.5 to 32 hours to replicate various mantle transport times. After each experiment the remaining coarse grain size fraction $(>63 \mu \mathrm{m})$ was removed from the distributor plate and sieved using a set of standard Tyler sieves. Then, all of the experimental rig components were flushed with deionised water to collect any ultra-fine particles. This water suspension along with any material collected in the water collection pail (Fig. 1) was measured for grain size using a Malvern Instruments Mastersizer 2000; a laser diffraction analyser capable of measuring particles suspended in water.

Our experiments build on previous work from the Engineering Sciences that has shown that particle attrition is highly dependent on a minimum of four governing parameters: the particle concentration suspended in the jet; the feed particle size distribution; the particle/gas velocity; and the particle residence time. Attrition is promoted by high particle concentrations, poorly sorted feed distributions, high differential velocities, and long residences times (Bemrose and Bridgwater 1987; Jones et al. 
2017). For us to compare our analogue results to nature and evaluate the attrition potential during kimberlite ascent, for example, we provide a dimensional analysis. Our experimental conditions are such that they fall within the same range of Reynolds numbers (Re; Equation 1) and Dimensionless particle concentrations ( $\phi$; Equation 2) expected in the natural system:

$$
\begin{array}{ll}
\mathrm{Re}=\rho \mathrm{uD} / \mu & \text { [Eqn. 1] } \\
\phi=\mathrm{v}_{0} / \mathrm{v}_{\mathrm{f}} & \text { [Eqn. 2] }
\end{array}
$$

where $\rho$ is the gas density, $\mathrm{u}$ the gas velocity, $\mathrm{D}$ the crack width or tube diameter, $\mu$ the gas dynamic viscosity, $\mathrm{v}_{0}$ the volume of the particles and $\mathrm{v}_{\mathrm{f}}$ the volume of the fluidized system. In detail, we calculate the minimum and maximum $\mathrm{Re}$ and $\phi$ predicted for the gas-rich fluidized head of the propagating dyke using crack widths $0.1<2.5 \mathrm{~m}$ and ascent velocities $0.25<8 \mathrm{~ms}^{-1}$. For all these parameters, we find both our experiments and natural kimberlite ascent lie within the same dimensionless turbulent, particleladen regime. Hence, this allows us to compare our experimental results to timescales and processes that operate within the gas-rich head of an ascending kimberlite dyke.

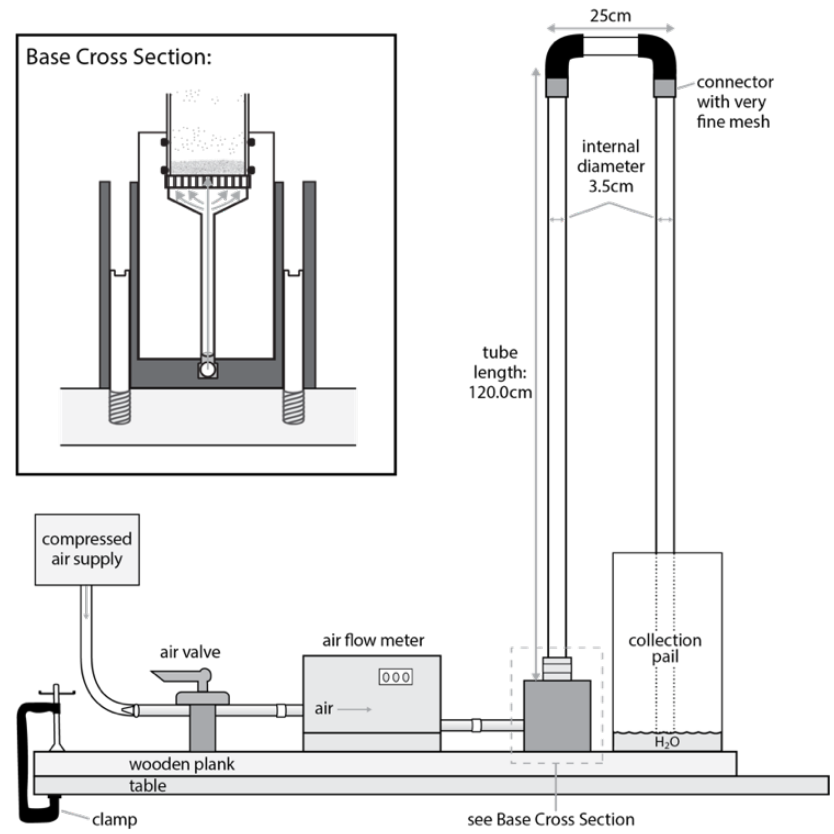

Figure 1: Diagram of the experimental attrition rig designed for this study.

\section{Results and Analysis}

In all experiments the gas feed and accociated bulk gas flow velocities of $1.13 \mathrm{~ms}^{-1}$ were sufficient to fluidize the olivine particles and sustain a turbulent flow regime. The initial packed bed height of 12.5 $\mathrm{mm}$ increased to $\sim 140 \mathrm{~mm}$ resulting in particles rapidly being transported within a particle-laden suspension. For all experiments the abundance of input feed material $(500 \mu \mathrm{m}-1 \mathrm{~mm})$ reduces during an experiment (Fig. 2a). This reduction in feed or parent particles is non-linear and faster at short attrition times. The reduction in parent particles can be attributed to the production of smaller $(<500$ $\mu \mathrm{m}$ ) daughter particles formed through fragmentation and abrasion (Fig. 2a). We find that the rate of fines production (defined as the mass of daughter particles, $\mathrm{m}_{\mathrm{d}}$ normalised to the feed mass, $\mathrm{m}_{0}$ ) is best described as:

$$
\mathrm{m}_{\mathrm{d}} / \mathrm{m}_{0}=a\left(1-e^{-b t}\right)[\text { Eqn. 3] }
$$

where $\mathrm{a}$ is the infinite time limit, $\mathrm{b}$ is the attrition rate constant and $\mathrm{t}$, the residence time. Experimental and modelled values for olivine attrition are shown in Fig. $2 \mathrm{~b}$. 

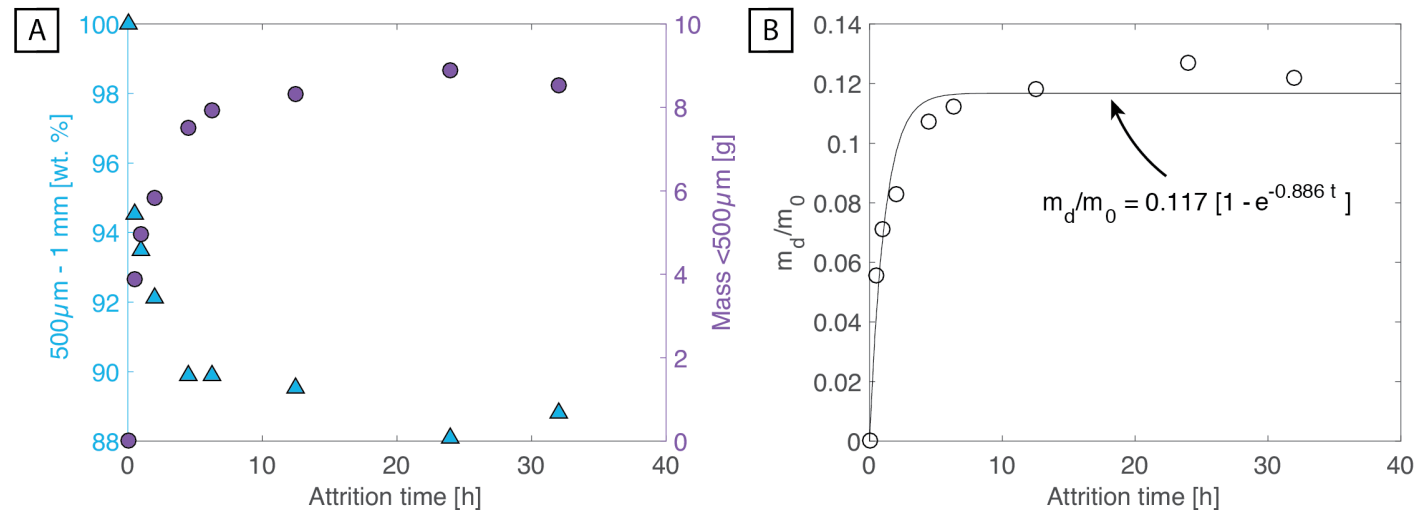

Figure 2: (a) Mass loss of feed (blue triangles) and mass gain in fines (purple circles) as a function of residence time. (b) Fines production model (Eqn. 3) for olivine attrition in a fluidized bed at $\operatorname{Re}=2690$ and $\phi=0.090$.

\section{Implications}

The experimental results have several implications for conceptual models of kimberlite ascent. They demonstrate that at short times (minutes to hours) olivine within a fluidized bed can be reshaped and resized efficiently. The dimensional similitude between our experiments and ascending kimberlite magmas supports a model whereby the shapes, sizes, and surface properties of the olivine cargo in kimberlite are derived by attrition processes operating in the fluidized ascending magma. During transport, attrition rapidly re-shapes, re-sizes and re-surfaces mantle olivine grains whilst continually creating a fine-grained sub-population. The fine chips of olivine have large surface area to volume ratios that accelerate chemical dissolution reactions, thereby removing the evidence of milling processes and facilitating the simultaneous modification of the melt composition. Such particles are susceptible to high rates of chemical dissolution; hence, rarely preserved in kimberlite. To fully understand the transportation of mantle cargo, particle interactions in the form of mechanical attrition, must be built into ascent models.

\section{References}

Arndt NT, Boullier A-M, Clément J-P, et al (2006) What olivine, the neglected mineral, tells us about kimberlite petrogenesis. eEarth Discuss 1:37-50.

Arndt NT, Guitreau M, Boullier A-M, et al (2010) Olivine, and the origin of kimberlite. J Petrol 51:573602.

Bemrose CR, Bridgwater J (1987) A review of attrition and attrition test methods. Powder Technol 49:97-126.

Brett RC, Russell JK, Andrews GDM, Jones TJ (2015) The ascent of kimberlite: Insights from olivine. Earth Planet Sci Lett 424:119-131. doi: http://dx.doi.org/10.1016/j.epsl.2015.05.024

Brooker RA, Sparks RSJ, Kavanagh JL, Field M (2011) The volatile content of hypabyssal kimberlite magmas: some constraints from experiments on natural rock compositions. Bull Volcanol 73:959981.

Jones TJ, Russell JK, Lim CJ, et al (2017) Pumice attrition in an air-jet. Powder Technol 308:298-305. doi: 10.1016/j.powtec.2016.11.051

Jones TJ, Russell JK, Porritt LA, Brown RJ (2014) Morphology and surface features of olivine in kimberlite: implications for ascent processes. Solid Earth 5:313.

Kamenetsky VS, Kamenetsky MB, Sobolev A V, et al (2008) Olivine in the Udachnaya-East kimberlite (Yakutia, Russia): types, compositions and origins. J Petrol 49:823-839.

Moussallam Y, Morizet Y, Massuyeau M, et al (2015) CO 2 solubility in kimberlite melts. Chem Geol 418:198-205.

Pilbeam LH, Nielsen TFD, Waight TE (2013) Digestion fractional crystallization (DFC): an important process in the genesis of kimberlites. Evidence from olivine in the Majuagaa kimberlite, southern West Greenland. J Petrol 54:1399-1425.

Russell JK, Porritt LA, Lavallée Y, Dingwell DB (2012) Kimberlite ascent by assimilation-fuelled buoyancy. Nature 481:352-356. 